\title{
Adjusting the Need for Speed: Assessment of a Visual Interface to
}

\section{Reduce Fuel Use}

\author{
Craig K. Allison ${ }^{1}$ \\ James M. Fleming² \\ Xingda Yan ${ }^{3}$ \\ Roberto Lot 4 \\ Neville A. Stanton ${ }^{5}$ \\ ${ }^{1}$ Solent University, Southampton, SO14 OYN, United Kingdom \\ ${ }^{2}$ Loughborough University, Loughborough, LE11 3TU, United Kingdom \\ ${ }^{3}$ University of Surrey, Guildford, GU2 7XH, United Kingdom \\ ${ }^{4}$ University of Padova, Padua, 35131, Italy \\ ${ }^{5}$ University of Southampton, Southampton, SO16 7QF, United Kingdom
}

\author{
Corresponding Author \\ Dr Craig Allison
}

School of Sport, Health and Social Sciences

Solent University, Southampton, UK

Email Craig.Allison@solent.ac.uk 


\begin{abstract}
Previous research has identified that fuel consumption and emissions can be considerably reduced if drivers engage in eco-driving behaviours. However, literature suggests that individuals struggle to maintain eco-driving behaviours without support. This paper evaluates an in-vehicle visual interface system designed to support ecodriving through recommendations based on both feedforward and feedback information. A simulator study explored participants' fuel usage, driving style, and cognitive workload driving normally, when eco-driving without assistance and when using a visual interface. Improvements in fuel-efficiency were observed for both assisted (8.5\%) and unassisted eco-driving (11\%), however unassisted eco-driving also induced a significantly greater rating of self-reported effort. In contrast, using the visual interface did not induce the same increase of reported effort compared to everyday driving, but itself did not differ from unassisted driving. Results hold positive implications for the use of feedforward in-vehicle interfaces to improve fuel efficiency. Accordingly, directions are suggested for future research.
\end{abstract}

\title{
Keywords
}

Fuel Use; Fuel Efficient Driving; In-Vehicle Interface Use; Eco-Driving 


\section{Practitioners' Summary}

Results from a simulator study comparing fuel usage from normal driving, engaging in unassisted eco-driving, or using a novel speed advisory interface, designed to reduce fuel use, are presented. Whilst both unassisted and assisted ecodriving reduced fuel use, assisted eco-driving did not induce workload changes, unlike unassisted eco-driving. 


\subsection{Introduction}

Automobile emissions contain a variety of harmful compounds including carbon monoxide, sulphur oxides and nitrogen oxides (Giacomin, Unno, Eichbauer, \& Atkins, 2019). Most notably however, vehicular emissions are a prime contributor to yearly increases in atmospheric levels of carbon dioxide $\left(\mathrm{CO}_{2}\right)$, (IEA, Key world energy statistics, 2017). The primary concern relating to the rising levels of atmospheric $\mathrm{CO}_{2}$ is due to its position as a greenhouse gas, causing global warming via an increase in radiative forcing of Earth's surface. These changes are predicted to have large scale negative economic, social and ecological impacts across multiple domains, including agriculture (Fischer, Shah, Tubiello, \& Van Velhuizen, 2005), biodiversity (Botkin, et al., 2007), and human health (McMichael, Woodruff, \& Hales, 2006).

The challenge of reducing automotive emissions is not novel and numerous techniques to minimise emissions have been trialled. The most direct approach is to develop more technologically capable and fuel efficient vehicular drivetrains (Piatkowski, Bronson, Marshall, \& Krizek, 2014), for example the use of hybrid, electric, or hydrogen fuel cell vehicles (Lorf, Martínez-Botas, Howey, Lytton, \& Cussons, 2013) and the use of cleaner alternative fuel sources such as compressed natural gas (Windecker \& Ruder, 2013). For many, the initial upfront cost of alternative drivetrains and the lack of a dedicated infrastructure to directly support a shift in drivetrain type (Yilmaz \& Krein, 2013) mean that they are not viable solutions in the immediate future.

Although some $\mathrm{CO}_{2}$ emission is unavoidable from the use of vehicles with 
internal combustion engines, multiple factors influence the quantity of fuel burned and the subsequent quantity of emissions. In addition to vehicular drivetrains (Chan, 2007) and mechanical systems (Vining, 2009), driving style is a key determinant of overall fuel usage (Mcllroy, Stanton \& Harvey, 2013). The adjustment of driving style and the adoption of techniques to reduce emissions is commonly referred to as eco-driving (Barkenbus, 2010). Rather than utilising technical development, ecodriving is a behavioural approach to emissions reduction, whereby driving style is adjusted to minimise fuel usage. Previous research has suggested that fuel usage can be reduced by approximately 5\% - 10\% (Martin, Chan, \& Shaheen, 2012) should drivers engage with eco-driving techniques. This holds true for both manual transmission vehicles and automatic ones where control over gear changes is handled by the vehicle and not the driver (Larue, Malik, Rakotonirainy \& Demmel, 2014). Importantly, these behaviours are not centred purely on the idea that drivers should slow down, as engagement in eco-driving can lead to notable fuel savings and emission reduction without dramatically increasing overall journey time (Birrell, Young, \& Weldon, 2013).

Eco-driving has become a widely discussed topic within academic literature (Allison \& Stanton, 2019) and holds a fundamental appeal as an intervention to cut transport related emissions, as it is accessible to all drivers (Birol, 2011), and does not require the financial outlay of the purchase of a new, modern vehicle (Saboohi \& Farzaneh, 2009). Despite these proposed benefits however, Delhomme, Cristea \& Paran, (2013) identified that eco-driving is reliant on several behaviours, such as precise timing of gear shifting, which are difficult for drivers to engage with long- 
term. Indeed, past studies have identified that the practice of eco-driving is associated with a noticeable increase in workload (Pampel, Jamson, Hibberd, \& Barnard, 2015). Drivers may simply feel that the required effort required to initially learn, engage, and maintain eco-driving behaviours are simply not worth it for the achieved financial saving (Dogan, Bolderdijk, \& Steg, 2014). Although fuel economy is of increasing importance to drivers (Turrentine \& Kurani, 2007), especially due to rising fuel prices (Heyes, Daun, Zimmermann \& Lienkamp, 2015), for many the estimated $£ 5$ a week saving (Beusen et al., 2009) is not viewed as a worthwhile investment for the level of required effort. One approach which is championed within literature to support drivers to eco-drive is via the use of specially designed in-vehicle interfaces (Tulusan, et al., 2012). The provision of feedback based on current and previous actions can encourage, support and reinforce eco-driving practices (Froehlich, et al., 2009; Meschtscherjakov, Wilfinger, Scherndl, \& Tscheligi, 2009). Numerous studies, both in simulators and real-world driving, have demonstrated the potential benefit of ecofeedback devices (Boriboonsomsin, Vu, \& Barth, 2010; Mensing, Bideaux, Trigui, Ribet, \& Jeanneret, 2014; Young, Birrell, \& Stanton, 2009).

However, one flaw common to such devices however is they typically do not adapt to the present driving context, instead only providing feedback on the fuel efficiency of drivers' past actions, which may be detrimental to the performance and user acceptance of such devices. The feedback provided is typically based on traditional eco-driving recommendations such as 'accelerate gently' and 'avoid braking'. A more effective approach may be to provide drivers with predictive, feedforward information based on their upcoming needs (Jamson, Hibberd, \& 
Jamson, 2015; McIlroy, Stanton \& Godwin, 2017; McIlroy, Stanton, Godwin \& Wood, 2017). Predictive systems may incorporate constraints relating to other driving objectives such as safety and collision avoidance (Dehkordi, Larue, Cholette, Rakotonirainy \& Rakha 2019). Research has demonstrated that a combination of feedforward advice and feedback is more effective than either feedforward or feedback alone (Vaezipour, Rakotonirainy, Haworth, \& Delhomme, 2018).

This paper seeks to extend previous research (Jamson, Hibberd, \& Jamson, 2015; McIlroy, Stanton \& Godwin, 2017) by presenting an evaluation of a novel assistance system that provides feedforward information based on a model of vehicle fuel consumption, prediction of the position of the preceding vehicle given its present velocity, and upcoming road geometry (Fleming, Yan, Allison, Stanton \& Lot, 2018). Uniquely, this system incorporates a model of typical driver preferences on aspects such as following distances and cornering speeds to 'coach' the driver into more fuelefficient behaviour as a modification of their natural driving style (Fleming, Yan, \& Lot, 2020). Using a repeated-measures study in a fixed-base driving simulator, its efficacy is compared to traditional eco-driving advice in terms of fuel economy, effects on driver speed, acceleration and braking, and measures of cognitive workload. This is achieved by evaluating these metrics in three conditions: everyday driving (to act as a control condition), unassisted eco-driving, and assisted ecodriving.

\section{Hypotheses}

Several hypotheses were generated for the current work:

1. Both assisted and unassisted eco-driving will record reduced fuel usage 
compared to everyday driving, consistent with alterations in driving style (Martin, Chan, \& Shaheen, 2012).

2. For both assisted and unassisted eco-driving, participants' driving styles will be altered to match common eco-driving recommendations, showing gentle acceleration and avoidance of braking (Barkenbus, 2010).

3. Use of the assisted eco-driving will not be more effortful than everyday driving, therefore will not induce workload greater than everyday driving (Meschtscherjakov, et al., 2009). In contrast, unassisted eco-driving will be associated with an increase in workload (Pampel, et al., 2015).

\subsection{Method}

\subsection{Design}

This study used a 3 (Condition) x 3 (Location) x 2 (Gender) mixed factorial design, with Condition and Location as within-subjects variables and Gender as a between-subjects variable. The independent variables were Condition (Control/ Unassisted eco-driving/ Assisted eco-driving) [Within], Location (Urban/ Rural/ Motorway) [Within] and gender (Male/ Female) [Between]. The dependent variables were overall fuel use, as measured in kilograms $(\mathrm{kg})$, speed, acceleration, braking dynamics and workload. 


\subsection{Participants}

Thirty-Six (36) participants (18 Males, 18 Female), aged $19-71$ years $(M=$ 28.92, $S D=12.82$ ) completed this study. All participants held a current full driving license (UK or International) and all participants had normal or corrected normal vision. Participants were required to complete the Ishihara Colour Blindness Test prior to completing this study to ensure eligibility. Ethical approval for this study was given by the University of Southampton Research Governance Team (ERGO Number 30746).

\subsection{Equipment and driving scenario}

The primary piece of equipment used was the Southampton University Driving Simulator (SUDS). SUDS consists of a fixed base right-hand drive Land Rover Discovery with an automatic transmission. Three screens were positioned in front of the vehicle to capture the forward projection of the road scene with 135degree field of view. A single screen behind the vehicle showed a projected rear-view image that could be seen in the vehicle's rear-view mirror. In addition, the vehicles' side mirrors presented projections of the road environment through LCD screens. Figure 1 presents a view of the SUDS laboratory. STISIM M500W wide-field-ofview driving simulation software was used as the simulation program. Throughout the drive, participants' interactions, including speed, acceleration, headway, throttle position and brake position were automatically logged by the simulator. 


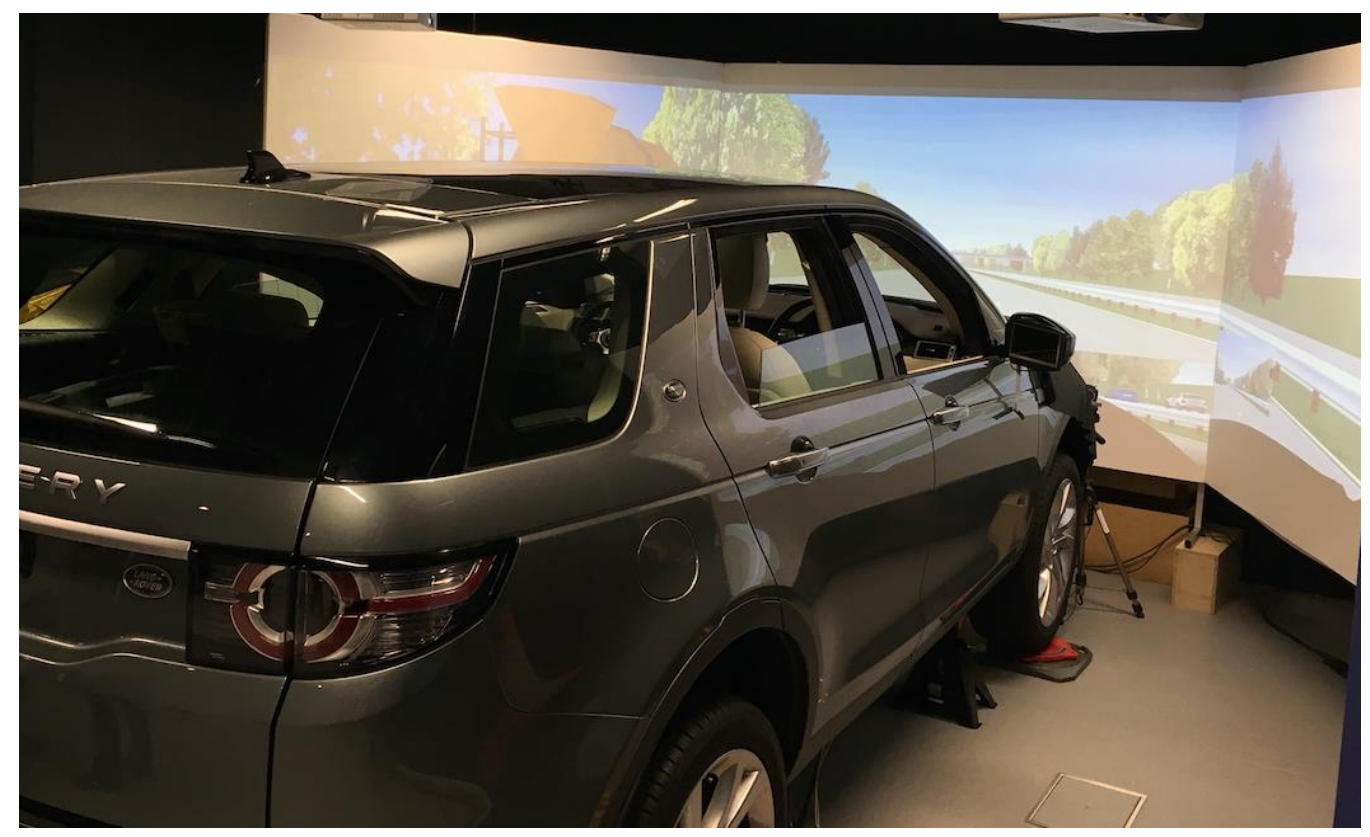

Figure 1. The University of Southampton Driving Simulator.

The simulated journey was modelled on a real-world route surrounding the University of Southampton and included realistic road curvature, traffic density for a mid-afternoon journey and localised landmarks. Development of this route is documented in Allison, Parnell, Brown and Stanton (2017). This route included the different road types of urban, rural and motorway sections of equal length. The route was 13 miles long and a drive lasted approximately 25 minutes. Urban areas of the route were interspersed at the beginning and end of the journey, whilst the motorway and rural sections appeared sequentially, separated by large roundabouts. Participants encountered six roundabouts as part of the route, which acted as junction decision points, whereby participants were required to significantly slow or come to a halt. There were two sets of pedestrian controlled traffic lights within the route, however these were set to green within the simulation. A map of the route participants was asked to drive is presented in Figure 2. Traffic levels encountered were based on early 
afternoon levels with no jams, with a stable level of traffic flow in the urban situation (approx. 10-20 vehicles per mile) and free-flowing traffic in the motorway and rural situations (<10 vehicles per lane per mile).

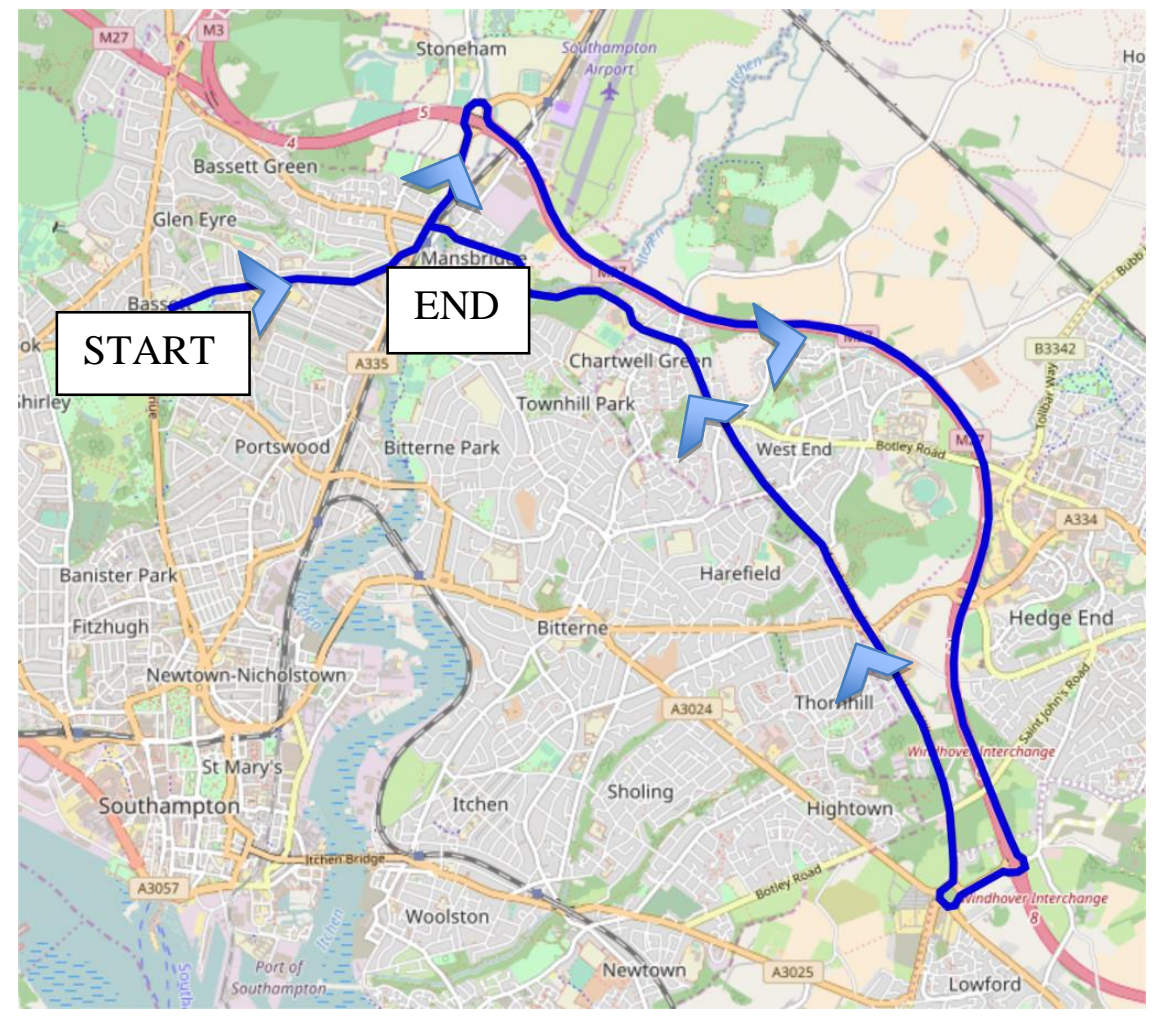

Figure 2. The driving route used in simulation, arrows indicate direction of travel.

As the simulator is a static vehicle, a digital speedometer was developed to inform participants of their current speed. This was included in a visual interface that was developed in C\# using Windows Presentation Foundation as a graphical library to display speed and RPM to the driver, based on real-time data from the STISIM simulation program. The resulting display was presented on a Microsoft Surface Pro tablet placed behind the steering wheel of the car, obscuring the simulator's nonfunctioning instrument cluster.

The speed recommendation was provided to the driver by annotating the 
digital speedometer. A green and yellow 'eco-band' was overlaid on to the speedometer to recommend a near-optimal speed range. Provided the participant ensured their speed was within the green region of the display they would be traveling in a fuel-efficient manor. The recommendation varied as a consequence of the current and imminent road environment, accounting for preceding cars and upcoming road geometry. A further yellow region allowed for some sub-optimal speed selection. A similar 'eco-speedometer' design was rated highly in perceived usefulness and user acceptance in previous research, however previous research lacked empirical testing of effectiveness (Meschtscherjakov, et al., 2009). An example of the annotated speedometer is provided within Figure 3.

When in use, the interface updates in real-time with the green eco-band stretching from zero speed to the current speed recommendation. This recommendation was generated by solving, in real-time, a numerical model predictive control optimisation problem that chose the throttle and braking action of the vehicle over the next 30 seconds to minimise fuel consumption, accounting for typical driver preferences on speed and following distances. To predict the position of the vehicle ahead of the driver over this 30 second horizon, the simplification is used that the leader vehicle will maintain its current speed. Road geometry was also considered, with curves driven below a certain speed for driver comfort and safety. The current speed recommendation is taken as the vehicle speed at 10 s into this 30 second prediction horizon and was updated continuously as the optimisation problem is resolved several times per second. The speed recommendation on the visual display was linearly interpolated between updates. The result is that the assistance system 
smoothly 'coaches' the driver into following an efficient speed profile, encouraging such behaviours as coasting down to gradually reduce speed before sharp corners or behind stopped vehicles at intersections. As this optimisation incorporated a model of vehicle energy losses due to braking, aerodynamics and rolling resistance, acceleration behaviour is recommended that leads to greater fuel-efficiency. A detailed technical description may be found in Fleming, Yan, Allison, Stanton, \& Lot (2018).

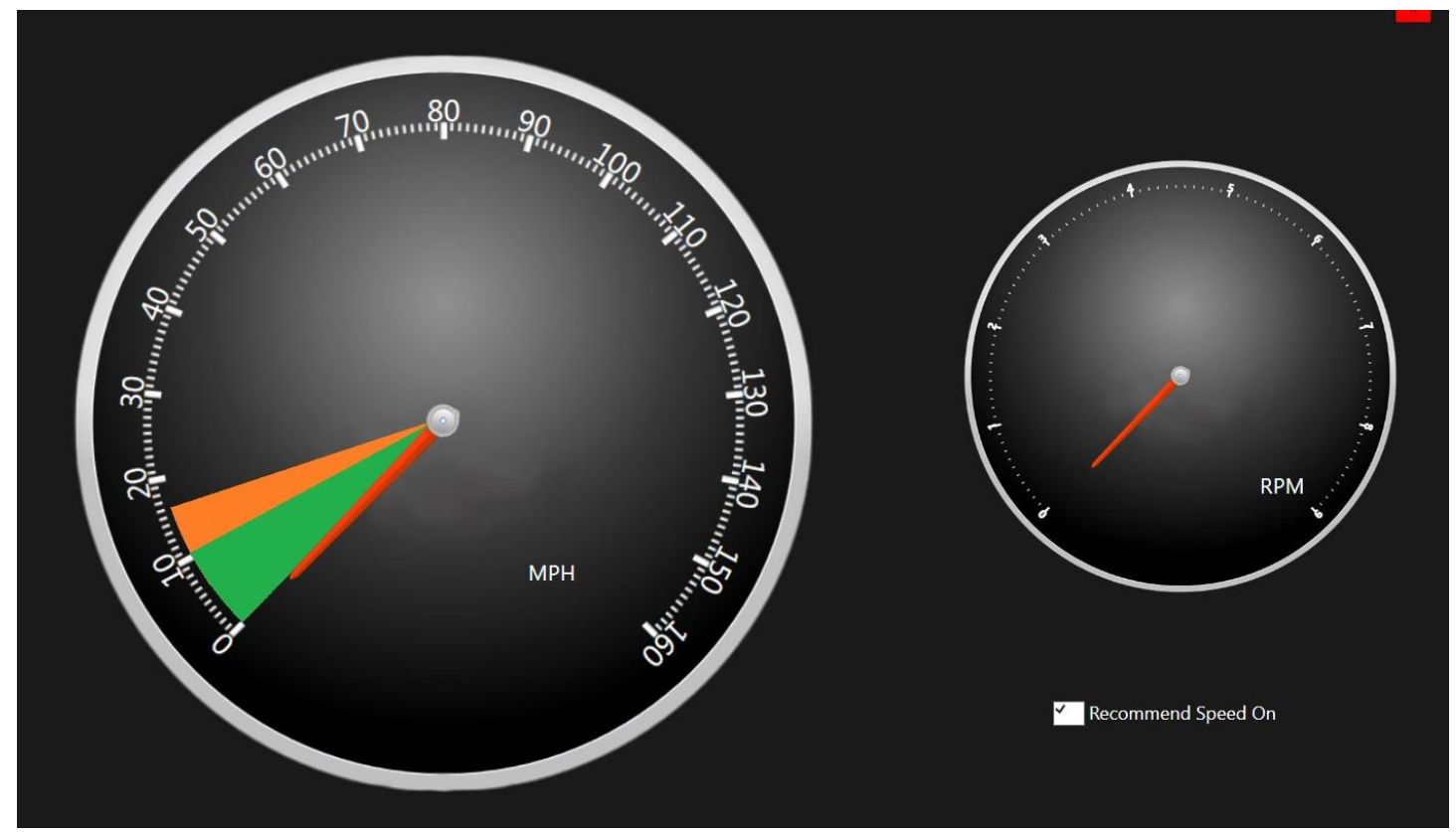

Figure 3. The speedometer used in the assisted eco-driving trial to display the recommended speed range. In the control and unassisted eco-driving conditions, the same display was used, but without the speed recommendation band.

\subsection{Procedure}

Upon entering the laboratory, participants were presented with an information sheet describing the aims of the research and outlining their ethical rights and a consent form. The experimenter verbally outlined the study to the participants and 
verbally restated their ethical rights. Participants were required to provide informed consent, and evidence of eligibility before the study could begin.

Prior to the start of the study, the driving simulator was adjusted to suit the individual participant's needs. Participants completed two practice drives within the simulator prior to the start of data collection. During these drives, participants were informed that the primary aim was to become accustomed to the simulator, the speedometer display and to acclimatise to the speed cues which were offered by the environment, for example the engine noise and optic flow pattern. Both practice drives used the same urban route lasting approximately 10 minutes. For the second practice drive, participants had access to the eco-driving assistance system. Participants were told that the recommended speed would reduce fuel usage if followed, but were not given details of how the recommendation was made, nor that it was a 10 second preview. Data from the practice trials were not analysed. Following completion of the practice drives, participants proceeded to the main study.

Three different driving conditions were assessed as part of the study: a Control condition in which drivers were asked to use their normal driving style, an unassisted eco-driving condition, whereby participants were presented with a series of ecodriving tips, including gentle acceleration, gentle braking and anticipation of traffic flow, prior the condition but no were not provided guidance during the drive (Unassisted), and assisted eco-driving condition (Assisted) in which the speed recommendation system described previously was used. To overcome potential order effects, the study was fully counterbalanced. Following completion of each simulated drive, participants completed the NASA-Task Load Index (Hart \& Staveland, 1988; 
NASA, 1986). Participants were encouraged to take a break following each drive, during which time the simulator reset.

Once participants had completed the three test trials and accompanying NASA-TLX, they were debriefed. The experimenter explained the aim of the study and presented participants with a debriefing form and compensation for their time. Participants were free to ask the experimenter questions about the study before leaving.

\subsection{Measures and Analysis}

STISIM simulation recorded numerous metrics based on participants' actions within the simulation. Participants' velocity, acceleration, throttle input and braking input were sampled at a rate of $10 \mathrm{~Hz}$. This provided time-series data that could then be post-processed into summary statistics to evaluate a participant's driving style. Denoting the instantaneous values of velocity, acceleration, and braking respectively as $v, a$ and $b$, these summary statistics included the average (mean) speed:

$$
\bar{v}=\frac{1}{T} \int_{0}^{T} v \mathrm{dt}
$$

where $T$ is the total journey time. The integral appearing in this expression, and other integrals appearing in this section, were approximated using the trapezoidal rule during processing of the time-series data. To give an indication of whether the driver 
was travelling at a steady speed or accelerating and decelerating often, the root-meansquare (RMS) deviation of the speed from the mean was also calculated as:

$$
v_{\text {RMS }}=\sqrt{\frac{1}{T} \int(v-\bar{v})^{2} d t}
$$

To evaluate if participants changed their acceleration behaviour, we also considered the time $T_{a}$ during which the vehicle was accelerating above a small threshold value $\left(0.5 \mathrm{~m} / \mathrm{s}^{2}\right)$, the mean acceleration during that time was then calculated as:

$$
\bar{a}=\frac{1}{T_{a}} \int_{T_{a}} a d t
$$

where the $T_{a}$ under the integral sign indicates that we are taking the average over only those times for which the vehicle was accelerating. As we include both mean acceleration and time spent accelerating as metrics, we may distinguish between hard accelerations over short periods of time, and lower accelerations over longer times. Similarly, we recorded the time $T_{b}$ during which the vehicle was braking, and the mean deceleration under braking was calculated as 


$$
\bar{b}=\frac{1}{T_{b}} \int_{T_{b}} b d t
$$

where again, the idea is that if drivers are braking more strongly or for longer in any condition, this should be clear from the calculated statistics.

Fuel usage was evaluated in post-processing using Simulink, using a detailed simulation model of the vehicle powertrain to estimate the fuel usage for each trial. This was carried out using the common 'quasi-static' approach which generates a power demand profile to follow the vehicle speed data obtained from the simulation (Guzzella \& Sciarretta, 2007). The model included a realistic engine map of fuel usage based on engine torque and RPM generated from 1-dimensional fluid dynamics simulations in Ricardo Wave, and additionally incorporated efficiency losses in the transmission, a typical gear-switching logic for an automatic gearbox, aerodynamic losses due to vehicle drag, and losses due to rolling resistance. The powertrain model used in the optimisation to find the recommended speed for the eco-driving assistance system was a simplified version of this simulation model that ignored powertrain energy losses.

In addition to metrics gained from the simulator relating to driving style and fuel use, participants completed the NASA-Task Load Index (NASA-TLX). This is a multivariate index to measure participants' subjective perceived workload (Hart \& Staveland, 1988), and is one of the most commonly used techniques to assess workload in practice (Stanton et al., 2013). It is comprised of six individual indices, 
designed to measure the 'Mental', 'Physical', 'Temporal Demand', 'Performance', 'Effort' and 'Frustration' components of overall cognitive load. NASA-TLX has been used across a variety of domains, including previous work exploring eco-driving (Jamson, Hibberd \& Jamson, 2015), driver distraction (Horberry et al., 2006) and aviation (Stanton et al. 2017; 2018).

\subsection{Results}

An alpha level of .05 was set for all statistical comparisons. KolmogerovSmirnov tests were used to verify the assumption of normality, then a series of 3 Condition (Control/ Unassisted Eco/ Assisted Eco) x 3 Location (Urban/ Rural/ Motorway) x 2 Gender (Male/ Female) mixed ANOVAs were used. The GreenhouseGeisser correction was used when data violated the assumption of sphericity. Where appropriate, post hoc paired-sample t-tests were calculated, with the Bonferroni correction for multiple comparisons being implemented, so that the unadjusted pvalues were multiplied by the number of pairwise comparisons made in each case (9) to give the adjusted p-values reported.

As driving style measures can be evaluated for each participant and calculated separately for each condition and road type (Location), this makes it possible to evaluate differences in driving styles in each case. This is followed by an analysis of workload in each condition from the NASA-TLX.

\subsection{ANOVAs}

To aid readability of the results, for the analysis of all considered driving 
metrics, main effects and interactions from the completed ANOVAs are presented in Table 1. Of clear interest within this table is the effect of condition.

Table 1. ANOVA for Condition, Location and Gender main effects and interactions.

\begin{tabular}{|c|c|c|c|c|c|}
\hline DV & Effect & df & $\mathbf{F}$ & $p$ & $\eta_{p}^{2}$ \\
\hline \multirow[t]{4}{*}{ Fuel Usage } & Condition & $1.67,56.86$ & 29.8 & $<0.001 * * *$ & 0.47 \\
\hline & Location & $1.57,53.20$ & 204 & $<0.001 * * *$ & 0.86 \\
\hline & Gender & 1,34 & 1.23 & 0.252 & -- \\
\hline & Condition $x$ Location & 4,136 & 6.69 & $<0.001 * * *$ & 0.16 \\
\hline \multirow[t]{4}{*}{ Average Speed } & Condition & 2,68 & 47 & $<0.001 * * *$ & 0.58 \\
\hline & Location & $1.32,44.95$ & 27.2 & $<0.001 * * *$ & 0.99 \\
\hline & Gender & 1,34 & 7.98 & $0.008^{*}$ & 0.19 \\
\hline & Condition $x$ Location & $2.33,79.35$ & 18 & $<0.001 * * *$ & 0.35 \\
\hline \multirow[t]{4}{*}{ RMS Speed Deviation } & Condition & $1.71,58.26$ & 11.8 & $<0.001 * * *$ & 0.26 \\
\hline & Location & $1.52,51.65$ & 41.1 & $<0.001 * * *$ & 0.55 \\
\hline & Gender & 1,34 & 1.09 & 0.303 & -- \\
\hline & Condition $x$ Location & $2.96,100.79$ & 4.67 & $0.004 * *$ & 0.12 \\
\hline \multirow[t]{4}{*}{ Mean Acceleration } & Condition & $1.49,50.69$ & 34.5 & $<0.001 * * *$ & 0.5 \\
\hline & Location & $1.45,49.30$ & 65.5 & $<0.001 * * *$ & 0.66 \\
\hline & Gender & 1,34 & 1.03 & 0.785 & -- \\
\hline & Condition $x$ Location & $2.57,87.62$ & 16.9 & $<0.001 * * *$ & 0.33 \\
\hline \multirow[t]{4}{*}{ Acceleration Time } & Condition & $1.57,53.29$ & 8.49 & $<0.001 * * *$ & 0.46 \\
\hline & Location & $1.67,56.71$ & 33.1 & $<0.001 * * *$ & 0.49 \\
\hline & Gender & 1,34 & $<1.00$ & 0.938 & -- \\
\hline & Condition $x$ Location & 4,136 & 4.53 & $0.002 * *$ & 0.12 \\
\hline
\end{tabular}

\subsection{Fuel Usage}

Figure 4 presents participants' fuel usage by location for each of the test trials, and Table 2 presents results from the post hoc analysis. Results demonstrated that the 
unassisted eco-drive recorded the lowest mean fuel usage and the control drive recorded the highest mean fuel usage. It should be noted that there was only a significant difference in fuel usage between the unassisted and assisted eco-drives for the motorway section of the route.

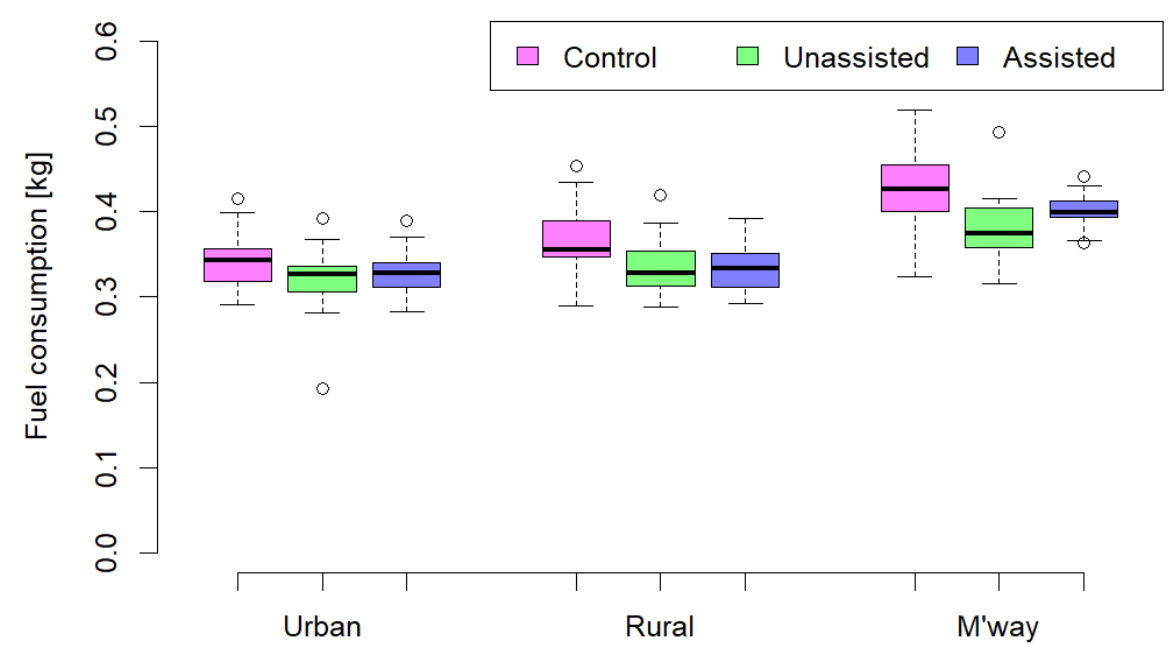

Figure 4. Participants mean fuel usage for the different locations, by condition

Table 2. Post-hoc tests, Condition x Location interaction for Fuel Usage.

\begin{tabular}{|c|c|c|c|c|c|c|c|c|c|}
\hline & \multicolumn{3}{|c|}{ Urban } & \multicolumn{3}{|c|}{ Rural } & \multicolumn{3}{|c|}{ Motorway } \\
\hline & $t(35)$ & $p($ adj $)$ & $\mathrm{MD}$ & $t(35)$ & $p(a d j)$ & $\mathrm{MD}$ & $t(35)$ & $p(a d j)$ & $\mathrm{MD}$ \\
\hline $\begin{array}{l}\text { Unassisted - } \\
\text { Control }\end{array}$ & -3.05 & $0.039 *$ & -0.019 & -4.82 & $<0.001 * * *$ & -0.032 & -7.52 & $<0.001 * * *$ & -0.048 \\
\hline $\begin{array}{l}\text { Assisted - } \\
\text { Control }\end{array}$ & -2.83 & 0.070 & -0.013 & -4.89 & $<0.001 * * *$ & -0.03 & -4.49 & $<0.001 * * *$ & -0.026 \\
\hline $\begin{array}{l}\text { Assisted - } \\
\text { Unassisted }\end{array}$ & 1.28 & 1.000 & 0.006 & 0.294 & 1.000 & 0.001 & 4.25 & $0.001 * *$ & 0.023 \\
\hline
\end{tabular}

\subsection{Average Speed}

Figure 5 ( $\mathrm{a}$ and $\mathrm{b}$ ) presents participants' average speed, by location, for each of the test trials. These figures confirm that average speed was highest during the 
motorway section of the route. The key difference between conditions was that participants travelled more slowly during the motorway section for the unassisted ecodriving condition. This is especially apparent when considering female participants, leading to the effect of gender identified within Table 1 . When considering the post hoc analysis, Table 3 demonstrates that significant differences were seen between both unassisted and assisted eco-driving when compared to control. The only significant difference between unassisted and assisted eco-driving occurred on the motorway, whereby unassisted eco-driving was associated with a lower mean speed.

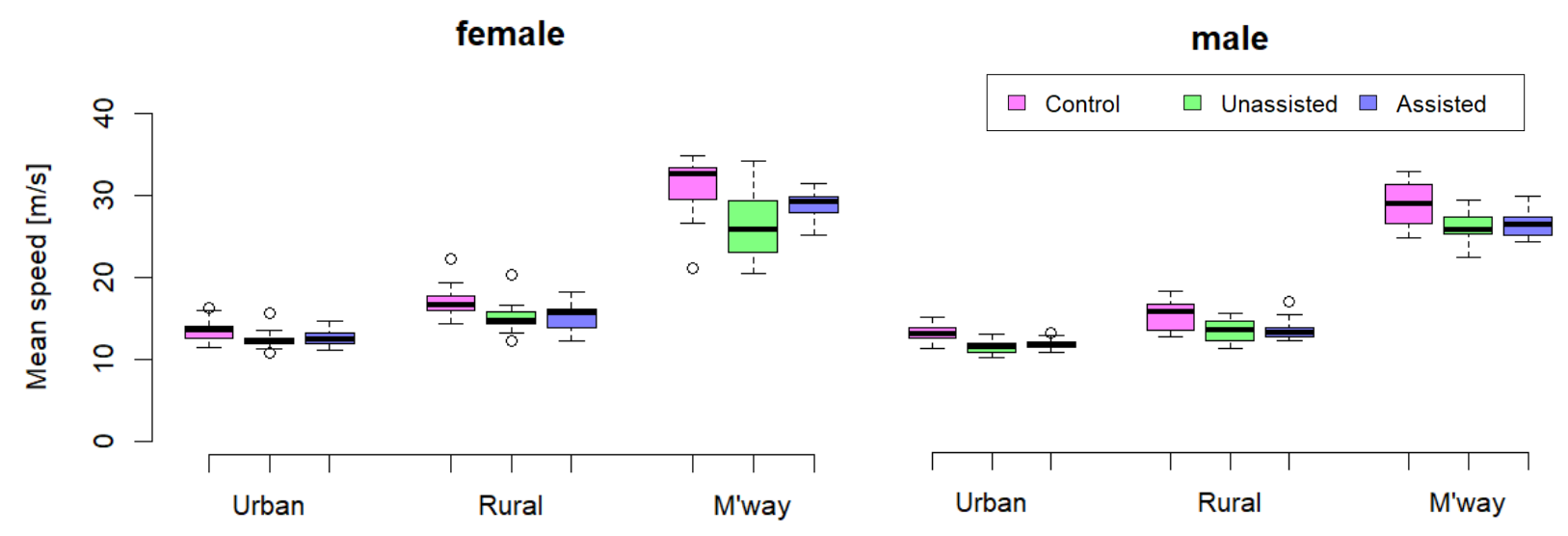

Figure 5. Participants' female (5a) and male (5b) mean speed.

Table 3. Post-hoc tests, Condition x Location interaction for Mean Speed.

\begin{tabular}{|c|c|c|c|c|c|c|c|c|c|}
\hline & \multicolumn{3}{|c|}{ Urban } & \multicolumn{3}{|c|}{ Rural } & \multicolumn{3}{|c|}{ Motorway } \\
\hline & $t(35)$ & $p($ adj $)$ & $\mathrm{MD}$ & $t(35)$ & $p($ adj $)$ & $\mathrm{MD}$ & $t(35)$ & $p($ adj $)$ & $\mathrm{MD}$ \\
\hline $\begin{array}{l}\text { Unassisted - } \\
\text { Control }\end{array}$ & -7.26 & $<0.001 * * *$ & -1.38 & -6.46 & $<0.001 * * *$ & -1.88 & -7.94 & $<0.001 * * *$ & -4.09 \\
\hline $\begin{array}{l}\text { Assisted - } \\
\text { Control }\end{array}$ & -6.87 & $<0.001 * * *$ & -1.17 & -6.66 & $<0.001 * * *$ & -1.79 & -6.11 & $<0.001 * * *$ & -2.53 \\
\hline $\begin{array}{l}\text { Assisted - } \\
\text { Unassisted }\end{array}$ & 1.85 & 0.654 & 0.21 & 0.388 & 1.000 & 0.09 & 3.03 & $0.041 *$ & 1.55 \\
\hline
\end{tabular}




$$
* p<.05, * * p<.005, * * * p<.001
$$

\subsection{Speed RMS Deviation}

Figure 6 presents participants' speed RMS deviation, by location, for each of the test trials. Whilst speed RMS deviation was typically highest during the rural section of the route, indicating greater changes in acceleration and deceleration, this is invariably linked to the route used and the nature of the rural roads within the simulation. It was seen that the control condition was associated with higher RMS speed deviation, significantly higher than both assisted and unassisted eco-driving in the rural section. When considering the effect of condition and location in more detail, participants were able to keep more consistent speeds in the assisted eco-driving condition within the urban section of the drive than during the unassisted eco-drive.

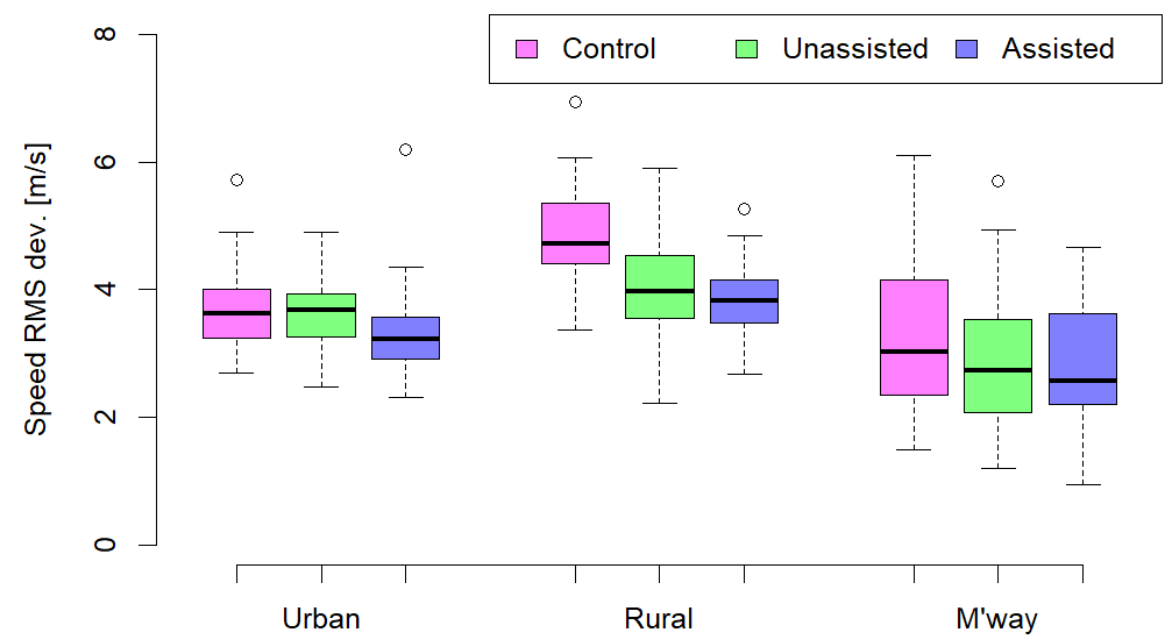

Figure 6. Participants' speed RMS deviation for the different locations, by condition.

Table 4. Post-hoc tests, Condition x Location interaction for Speed RMS Deviation. 


\begin{tabular}{lccccccccc} 
& $t(35)$ & $p(a d j)$ & $\mathrm{MD}$ & $t(35)$ & $p($ adj $)$ & $\mathrm{MD}$ & $t(35)$ & $\begin{array}{c}p \\
(\text { adj })\end{array}$ & $\mathrm{MD}$ \\
\hline Unassisted- & 0.17 & 1.000 & 0.019 & -4.52 & $<0.001^{* * *}$ & -0.71 & -2.02 & 0.459 & -0.492 \\
Control & -2.55 & 0.137 & -0.339 & -6.79 & $<0.001 * * *$ & -0.984 & -2.04 & 0.444 & -0.495 \\
Assisted - Control & -3.62 & $0.008^{*}$ & -0.357 & -2.04 & 0.444 & -0.275 & -0.01 & 1.000 & -0.003 \\
Assisted - & & & &
\end{tabular}

$* p<.05, * * p<.005, * * * p<.001$

\subsection{Mean Acceleration}

Figure 7 presents participants' mean acceleration, by location, for each of the test trials, showing that greatest mean acceleration was seen in the control condition and lowest mean acceleration was recorded in the unassisted eco-driving condition, most apparently during the motorway section of the route. The post hoc analysis (Table 5) demonstrated significant differences between participants' recorded mean acceleration for the control and unassisted eco-driving conditions for both the motorway and urban sections of the drive. Post hoc analysis also revealed a significant difference between mean acceleration for the assisted and unassisted ecodrivers during the motorway section.

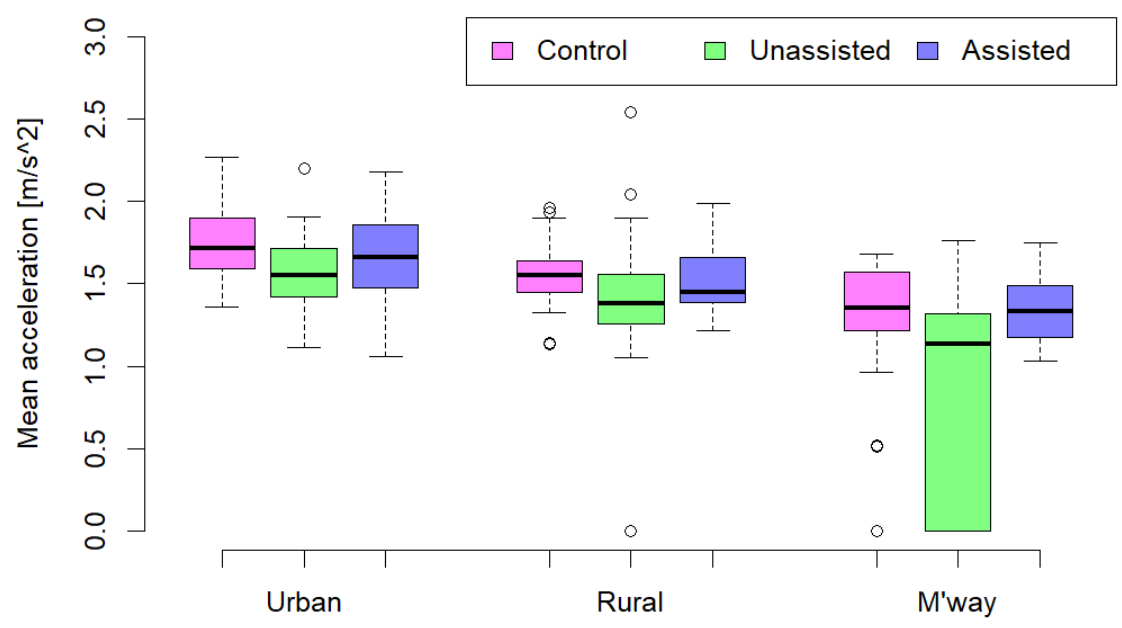


Figure 7. Participants' mean acceleration, by condition.

Table 5. Post-hoc tests, Condition x Location interaction for Mean Acceleration.

\begin{tabular}{|c|c|c|c|c|c|c|c|c|c|}
\hline & \multicolumn{3}{|c|}{ Urban } & \multicolumn{3}{|c|}{ Rural } & \multicolumn{3}{|c|}{ Motorway } \\
\hline & $t(35)$ & $p(a d j)$ & MD & $\mathrm{t}(35)$ & $\begin{array}{c}p \\
(\text { adj })\end{array}$ & MD & $\mathrm{t}(35)$ & $p(a d j)$ & MD \\
\hline $\begin{array}{l}\text { Unassisted - } \\
\text { Control }\end{array}$ & -4.2 & $0.002 * *$ & -0.187 & -2.52 & 0.147 & -0.148 & -4.57 & $<0.001 * * *$ & -0.432 \\
\hline Assisted - Control & -1.96 & 0.518 & -0.072 & -0.86 & 1.000 & -0.028 & 0.74 & 1.000 & 0.04 \\
\hline $\begin{array}{l}\text { Assisted - } \\
\text { Unassisted }\end{array}$ & 2.69 & 0.099 & 0.115 & 1.9 & 0.588 & 0.12 & 4.72 & $<0.001 * * *$ & 0.472 \\
\hline
\end{tabular}

$* p<.05, * * p<.005, * * * p<.001$

\subsection{Acceleration Time}

To standardise the acceleration time metric across participants, this value was considered as a percentage of the journey time in each location. It is clear from Figure 8 that participants spent more time accelerating in the control condition for all locations. In contrast, considerably less acceleration time was seen in the unassisted eco-drive condition. Post hoc tests (Table 6) indicated significantly less acceleration in the unassisted eco-driving condition than either the control or assisted eco-drive. 


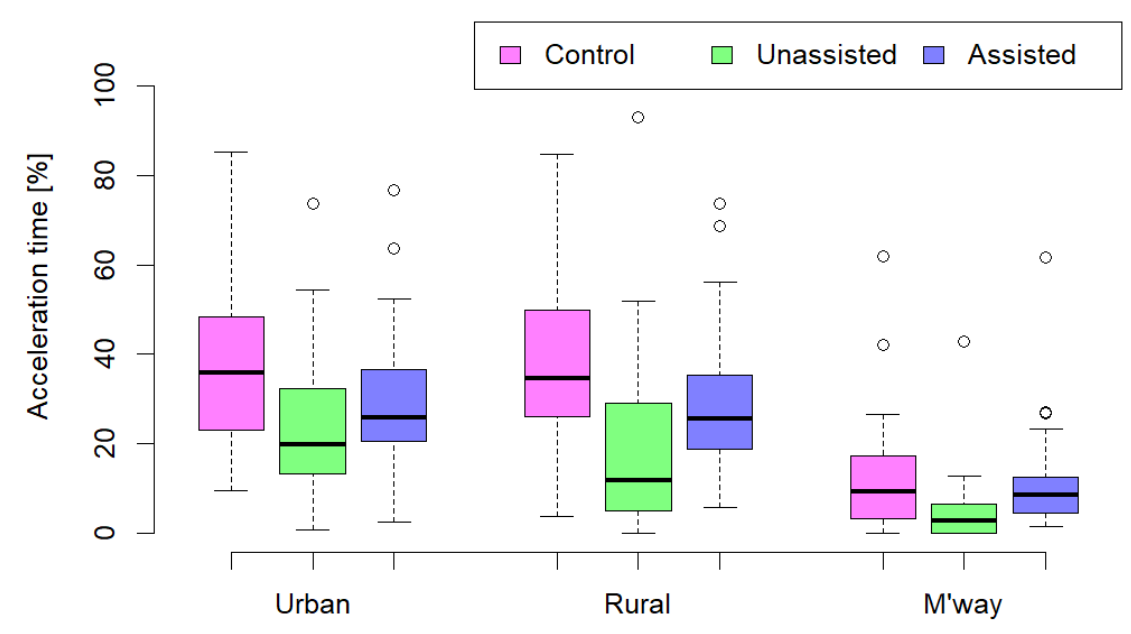

Figure 8. Participants' mean acceleration time in seconds.

Table 6. Post-hoc tests, Condition x Location interaction for Acceleration Time.

\begin{tabular}{|c|c|c|c|c|c|c|c|c|c|}
\hline & \multicolumn{3}{|c|}{ Urban } & \multicolumn{3}{|c|}{ Rural } & \multicolumn{3}{|c|}{ Motorway } \\
\hline & $t(35)$ & $p(a d j)$ & MD & $t(35)$ & $p(a d j)$ & MD & $t(35)$ & $p$ (adj) & MD \\
\hline $\begin{array}{l}\text { Unassisted - } \\
\text { Control }\end{array}$ & -5.04 & $<0.001 * * *$ & $\begin{array}{c}- \\
15.34\end{array}$ & -5.53 & $<0.001 * * *$ & -18.6 & -5.33 & $<0.001 * * *$ & -7.73 \\
\hline $\begin{array}{l}\text { Assisted - } \\
\text { Control }\end{array}$ & -3.4 & $0.016^{*}$ & -8.97 & -2.9 & 0.058 & -9.15 & -0.79 & 1.000 & -1.24 \\
\hline $\begin{array}{l}\text { Assisted - } \\
\text { Unassisted }\end{array}$ & 3.44 & $0.014^{*}$ & 6.38 & 3.16 & $0.029^{*}$ & 9.45 & 5.77 & $<0.001 * * *$ & 6.5 \\
\hline
\end{tabular}

$$
* p<.05, * * p<.005, * * * p<.001
$$

\subsection{Mean Braking Deceleration}

Figure 9 presents mean braking deceleration for each of the conditions and locations explored within the current study. Braking deceleration was relatively consistent in the different conditions and varied most noticeably with location, although was consistently lowest in the unassisted eco-drive trial. Post-hoc tests (table 7) reinforced the view that limited differences were observed between conditions and 
locations, with the exception that unassisted rural driving recorded significantly lower braking deceleration than the same location within the control condition.

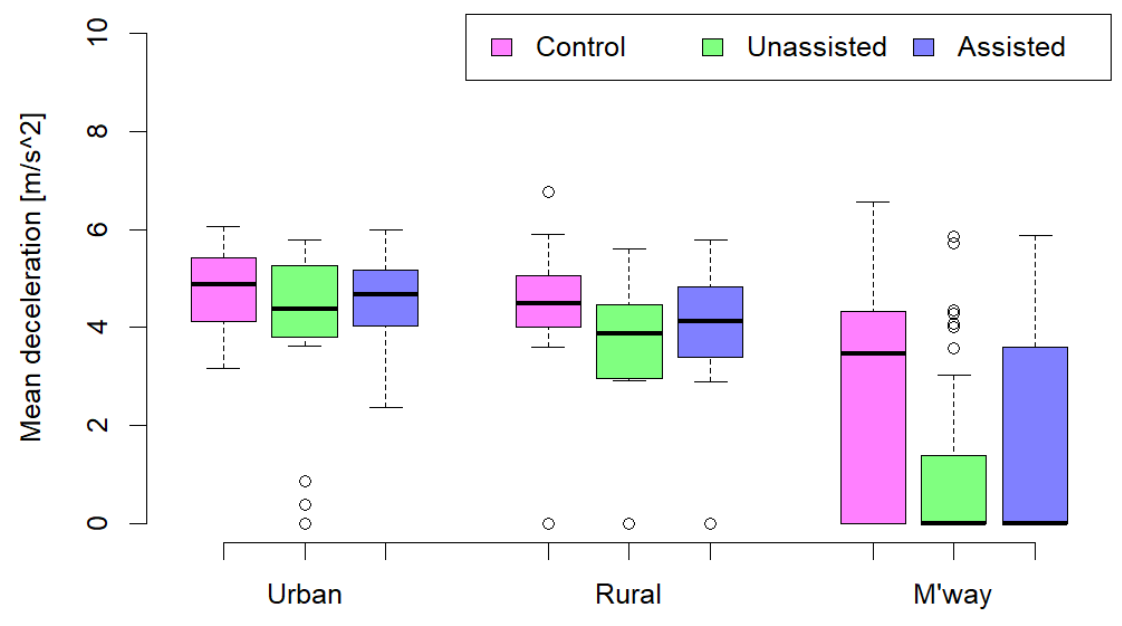

Figure 9. Participants' mean braking deceleration.

Table 7. Post-hoc tests, Condition x Location interaction for Braking Deceleration.

\begin{tabular}{lccccccccc}
\hline & & Urban & \multicolumn{3}{c}{ Rural } & \multicolumn{3}{c}{ Motorway } \\
\hline & $t(35)$ & $p(a d j)$ & MD & $t(35)$ & $p($ adj $)$ & MD & $t(35)$ & $p($ adj $)$ & MD \\
\hline Unassisted - & -2.47 & 0.168 & -0.55 & -3.39 & $0.016^{*}$ & -1.14 & -2.84 & 0.068 & -1.36 \\
Control & 1.27 & 1.000 & 0.24 & 2.21 & 0.302 & 0.86 & -1.76 & 0.777 & -0.87 \\
Assisted - Control & -1.14 & 1.000 & -0.31 & -0.74 & 1.000 & -0.28 & -1.27 & 1.000 & -0.49 \\
Assisted - & & & & & & & & & \\
Unassisted & & &
\end{tabular}

$* p<.05, * * p<.005, * * * p<.001$

\subsection{Braking Time}

As limited differences were observed relating to braking deceleration, overall braking time was also considered. It is clear from Figure 10 that the control condition was associated with the greatest mean braking time, with both eco-driving conditions (unassisted and assisted) being associated with less braking. Exploration of post-hoc 
analysis (table 7) demonstrated that both unassisted and assisted eco-drives were associated with significantly less braking time in both rural and urban sections of the route, compared to the control drives. The eco-driving conditions did not significantly differ from each other.

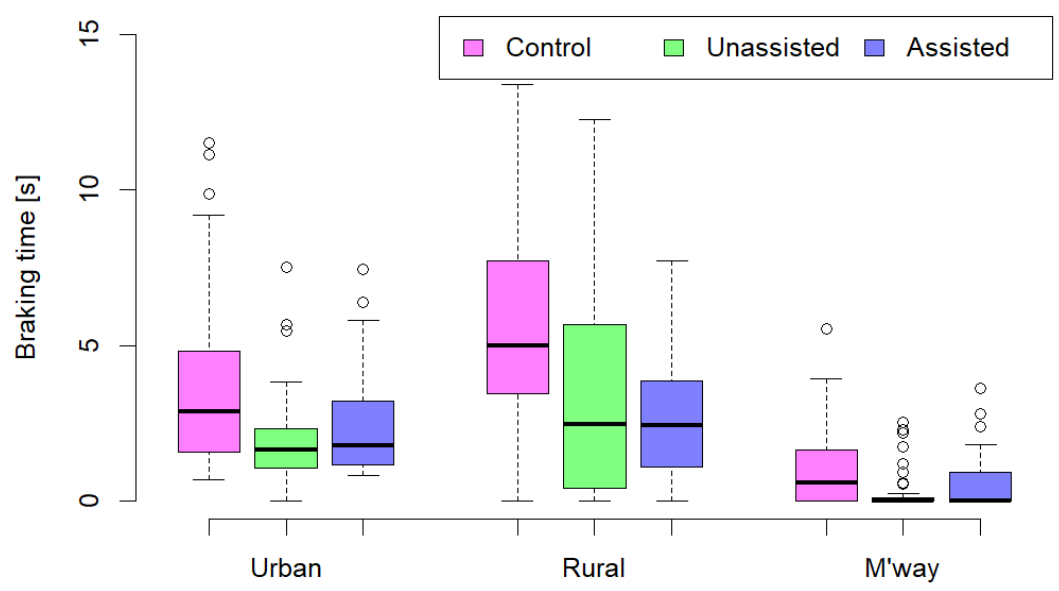

Figure 10. Participants' mean braking time in seconds.

Table 7. Post-hoc tests, Condition x Location interaction for Braking Time.

\begin{tabular}{lccccccccc}
\hline & \multicolumn{3}{c}{ Urban } & \multicolumn{3}{c}{ Rural } & \multicolumn{3}{c}{ Motorway } \\
\hline & $t(35)$ & $p(a d j)$ & MD & $t(35)$ & $p(a d j)$ & MD & $t(35)$ & $\begin{array}{c}p \\
(\text { adj })\end{array}$ & MD \\
\hline Unassisted - & -3.61 & $0.009^{*}$ & -1.75 & -3.22 & $0.025^{*}$ & -2.25 & -2.67 & 0.104 & -0.69 \\
Control & 3.22 & $0.025^{*}$ & 1.41 & 6.17 & $<0.001^{* * *}$ & 2.96 & 2.24 & 0.286 & 0.51 \\
Assisted - Control & -1.28 & 1.000 & -0.34 & 1.2 & 1.000 & 0.71 & -1 & 1.000 & -0.18 \\
Assisted - & & & & & & & & &
\end{tabular}

$$
* p<.05, * * p<.005, * * * p<.001
$$

\subsection{Workload}

In addition to objective data relating to participants' performance, subjective data was also collected relating to participants' overall level of workload following 
each drive, using the NASA-TLX. Each subscale of the NASA-TLX is presented separately and separately compared across the three conditions of the study using a series of 3 Condition (Control/ Unassisted/ Assisted) x 2 Gender (Male/ Female) mixed ANOVAs. NASA-TLX scores recorded across the three conditions explored within the current study are presented in Figure 11. 


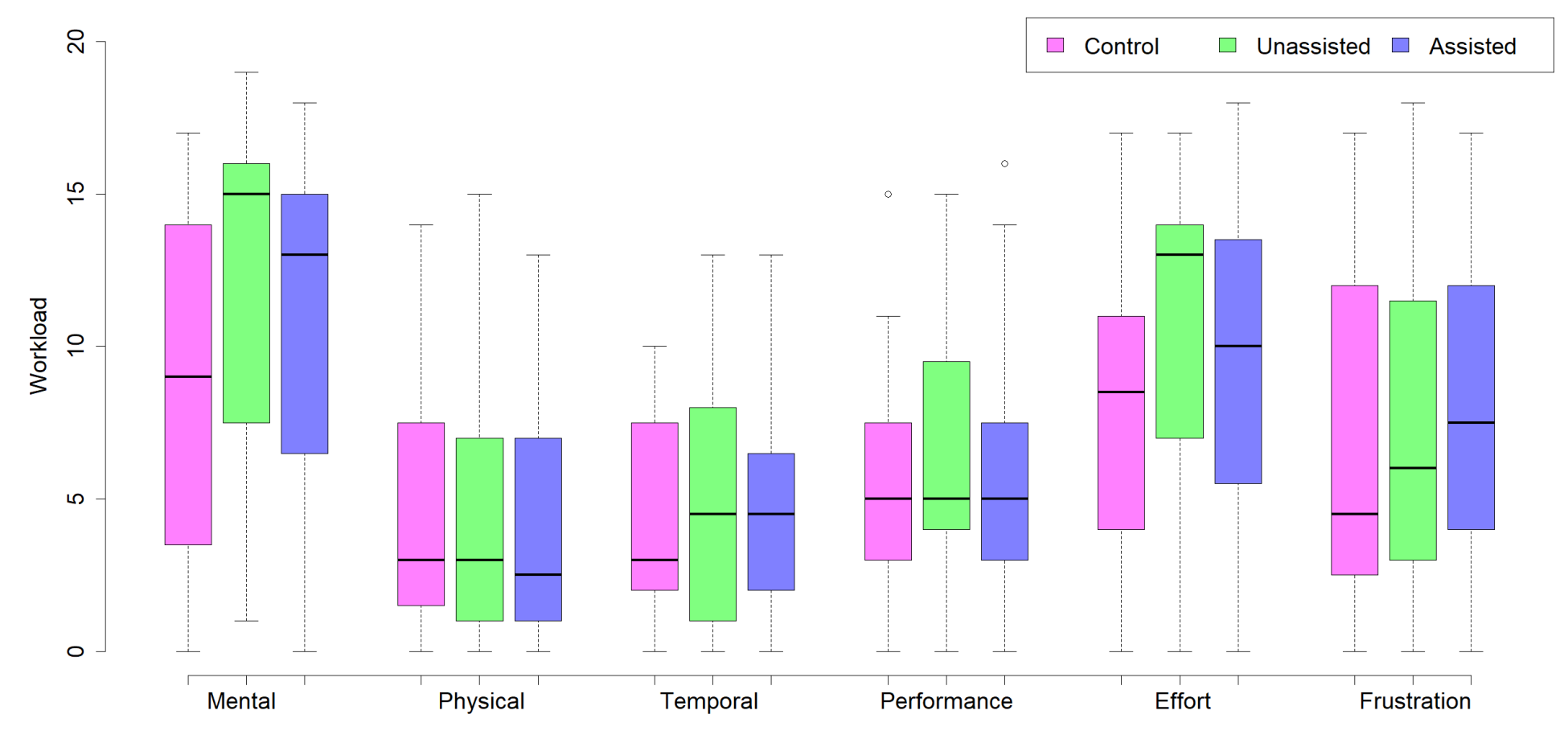

Figure 11. Participants' workload as measured by NASA-TLX. 
For mental workload, a main effect of condition was identified, $F(2,68)=$ $11.40, p<.05, \eta p^{2}=.25$. Participants' self-reported mental workload varied between the three trials. No effect of gender $(F<1, n s)$ and no significant interaction between condition and gender $(F<1, n s)$ was observed. Post hoc tests showed a significant difference between mental workload for control drive $(M=8.83, S D=5.39)$ and the unassisted eco-driving drive $(M=12.39, S D=5.09) ; t(35)=-4.85, p=.001$. A significant difference was also identified in mental workload between the control drive and assisted eco-drive $(M=11.47, S D=4.92), t(35)=-3.38, p=.005$. There was no significant difference between the unassisted and assisted conditions; $t(35)=1.13$, $p=.26, n s$.

Examination of participants' effort ratings demonstrated a significant main effect of condition $\left(F(2,68)=7.42, p<.05, \eta p^{2}=.18\right)$, suggesting that condition impacted participants' rating of required effort. No effect of gender $(F<1, n s)$ or interaction between condition and gender $(F<1, n s)$ was observed suggesting that gender did not influence effort ratings. Post hoc tests revealed a significant difference in participants' ratings of effort for the control drive $(M=8.22, S D=4.01)$ and the unassisted eco-drive $(M=10.86, S D=4.52) ; t(35)=-3.67, p=.001$, participants rated the required effort higher in the unassisted eco-drive than the control drive. However, there was no significant difference in effort rating between the control drive and assisted eco-drive $(M=9.36, S D=4.88) ;(p=.174)$, or between the unassisted and assisted eco-drives $(p=.144)$.

All remaining subscales of the NASA-TLX failed to identify a main effect of condition (Physical $(F<1, n s)$, Temporal $(F<1, n s)$, Performance $(F<1, n s)$, Frustration 
$(F(1.71,58.02)=1.15, n s)$

\subsection{Discussion}

Results suggest that participants' fuel usage was significantly reduced both when they were required to eco-drive without assistance and when provided with the speed recommendation system (3.2 Fuel Usage), supporting Hypothesis 1. Greatest fuel savings were observed within the unassisted eco-driving trial. Results suggest that the induced savings in both unassisted and assisted trials were due to a variety of factors, including travelling at a reduced speed (3.3 Average Speed) and recording more consistent speeds throughout the drives (3.4 Speed RMS Deviation), and recording reduced acceleration (3.5 Mean Acceleration; 3.6 Acceleration Time), supporting Hypothesis 2. Consistent with Hypothesis 3, despite the fuel savings seen within the unassisted eco-driving trial, this was seen at the cost of greater mental workload, specifically higher self-reported effort (3.9 Workload). Further Supporting Hypothesis 3, whilst the assisted drive was associated with higher mental workload than the control drive, participants did not rate this interface as any more effortful than the control drive.

Prior to discussion of the differences between conditions it is worth considering the effects of location that were identified within the current study. The finding that participants fuel usage was greatest on the motorway, followed by the rural routes, followed by urban routes was as expected. This is because fuel usage is fundamentally linked to the speeds that participants would travel on these roads, which are signposted at $70 \mathrm{mph}, 40 \mathrm{mph}$ and $30 \mathrm{mph}$ respectively. Indeed, results of the 
current study demonstrate that location was a key determinant of participants' general driving behaviours. This reinforces the view that drivers are active in modifying their behaviours based on the environment they find themselves in, which vary based upon numerous factors including legal speed limits, road curvature and traffic conditions. Participants ability to adapt their driving behaviour was also seen between the different conditions. Participants' fuel savings in both the assisted and unassisted ecodriving conditions, reflected fundamental changes in driving style by the participants. To examine this in greater detail, participants' acceleration and braking dynamics were considered.

\subsection{Effects on driving style}

The results for mean acceleration (3.5 Mean Acceleration) confirm the view that the unassisted eco-drive was associated with significantly lower mean acceleration than the control drive. Interestingly other comparisons failed to reach required levels of significance. This suggests that participants used more gentle acceleration in the unassisted condition than the control condition, but not gentler than in the assisted condition. Of interest however was the limited acceleration participants used when on the motorway, further supported by data relating to acceleration time (3.6 Acceleration Time), suggesting that within the unassisted condition participants accelerated to a desirable speed and then sought to maintain this speed, actions not possible on both the urban and rural sections of the route due to the presence of other road users, road geometry and layout.

It was seen that participants' acceleration profiles differed between conditions, 
indeed participants recorded greatest acceleration time within the control condition and least within the unassisted condition (3.6 Acceleration Time). As the acceleration profile also impacted fuel usage, the band was not as effective at suppressing participants' acceleration as unassisted eco-driving was. Rather the assistive system was ineffective at moderating participants' acceleration, with participants' rapidly accelerating to reach the maximum speed. This suggests further work is needed to investigate how to encourage participants to engage in gentle acceleration, specifically how the display can be refined to encourage participants to gently accelerate towards the recommended speed. The fact that participants were able to modify their behaviour to minimise fuel use reinforces however that participants are able to rapidly and effectively eco-drive following minimal guidance, but require encouragement to initially engage in these behaviours.

\subsection{Effects on fuel consumption}

Participants' fuel usage was significantly reduced both when they were required to eco-drive without assistance and when they had access to the feedforward speed optimisation system (3.2 Fuel Usage). These savings were on average $11 \%$ and $8.5 \%$ of the fuel used in the control trial, respectively. The additional fuel savings recorded within the unassisted condition were associated with participants spending significantly less time accelerating within this trial compared to the other conditions, demonstrating that participants modified their driving behaviour beyond simply slowing down and maintaining consistent speeds.

Despite all the additional savings associated with both the assisted and 
unassisted eco-driving beyond slowing, it would be remiss to ignore that participants travelled at a lower speed during both the unassisted and assisted eco-driving conditions, particularly on the motorway (3.3 Average Speed). This causes lowering of losses from aerodynamic drag, which is typically a considerable contribution to overall fuel consumption at speeds of greater than 50mph (Gillespie, 1997). The fuel savings seen within the assistive condition within the motorway of the route were not expected, as although the developed system is reactive to road events and curvature, the motorway is characterised by free-flowing traffic and limited curvature, and therefore would recommend a speed close to the speed limit of 70mph. However, the system recommending that participants travelled at or below the speed limit acted to reinforce legal limits, limits that participants typically exceeded in the control condition, making this drive more legal, potentially safer and offering reduced emissions as a by-product of the reduced maximum speed.

\subsection{Effects on cognitive workload}

Despite the fuel savings induced by unassisted eco-driving, it was seen from the NASA-TLX results (3.9 Workload) that this was at the cost of greater mental workload and higher self-reported effort, supporting previous research (Pampel et al., 2015). In contrast, whilst assisted eco-driving was also associated with higher mental workload than the control drive, this was not statistically significant. This finding conflicts with previous research examining interface use and eco-driving which suggested that eco-driving with a visual interface induces greater workload than unassisted eco-driving (Jamson, Hibberd, Jamson, 2015). Similarly, Lee, Lee and Lim 
(2010) documented increased workload when participants were asked to use a visual interface designed to promote eco-driving. This suggests that the design of visual ecodriving assistance has a fundamental effect not only on its effectiveness in terms of fuel reduction but also how hard participants must work to achieve this saving. Despite the overall positive results, no statistical difference was observed in effort ratings between the assisted and unassisted eco-driving, which may not have been the case if a greater sample size was used in the study.

\subsection{Limitations}

As a simulator-based study there are several limitations that should be acknowledged. The first key limitation is that a model of fuel efficiency was used to measure fuel use, which may differ from real-world usage. In addition, the study did not examine participants' qualitative opinions of the assistive system, which could provide useful feedback regarding whether participants liked such a representation of recommended speed and whether they would be willing to interact with the speed recommendation system outside of the simulator and controlled laboratory conditions. Consideration of the potential negative effects of the speed recommendation system is also needed prior to on-road testing, where effects such as distraction linked to the speed recommendation system could have considerable safety implications.

\subsection{Avenues for future work}

This study has highlighted several avenues for further research. Firstly, this study has revealed that despite the improvements offered by the assistance system in terms of fuel use, it could be improved further to more closely reflect the fuel use 
recorded within the eco-trial. This improvement could be achieved by providing drivers with an indication of when to release the accelerator to encourage greater coasting, reducing the need for braking, and guidance regarding the rate to accelerate to reach a recommended speed. Previous approaches to encouraging greater coasting behaviour have combined the use of haptic information through the accelerator with other stimuli to provide participants information on the best time to reduce acceleration (Jamson, Hibberd \& Merat, 2013). It is therefore possible a system such as the one considered in the current study could be combined with alternative feedback modalities. As no statistical difference was observed in effort ratings between the assisted and unassisted eco-driving, future work is also needed to further develop the visual interface to facilitate participants eco-driving and explore participants' subsequent interactions in more detail.

In addition to opportunities relating to refinements to the assistance system, there is the potential and need to test the feedforward speed optimisation system within the real road environment. Two hurdles must be addressed for this system to be viable within production vehicles. The first is suitable integration with on-board vehicle sensors, such as radar and LIDAR systems, and the vehicle engine management system, a non-trivial task (Allison, Fleming, Yan, Stanton, \& Lot, 2019). The second obstacle is ensuring safe, accurate and meaningful predictions from the system within a volatile road environment. Within the simulated conditions explored all traffic behaviour is pre-scripted and hence predictable, but in the real-world this is not the case. The increasing potential for future connected and autonomous vehicles (Banks, Stanton, Burnett \& Hermawati, 2018) however provides ideal impetus for the 
need to develop and utilise feedforward technologies, as explored within the current work.

\subsection{Conclusion}

The desire to reduce emissions and increase the fuel economy associated with road vehicles is shared by governments, automotive manufacturers and drivers. This study demonstrated success in the assessment of a novel feedforward speed optimisation display to coach a driver into fuel-efficient driving and provided evidence that such a device can be used to reduce fuel usage compared to everyday driving behaviours. Although the display was not as effective at reducing total fuel usage as when participants were specifically asked to eco-drive, it was found that participants' success at unassisted eco-driving was at the cost of increased selfreported effort suggesting that participants may struggle to maintain this behaviour outside of laboratory conditions. Further refinement of the visual interface is possible to facilitate its use.

\section{Acknowledgements}

This work was funded by the UK Engineering and Physical Sciences Research Council (EPSRC) grant EP/N022262/1 “Green Adaptive Control for Future Interconnected Vehicles" (www.g-active.uk).

The authors would like to offer thanks to all participants who gave their time to participate within the study presented within the current work.

Preliminary abridged fuel use data from this study was presented at 2nd 
International Conference on Intelligent Human Systems Integration IHSI 2019 (San Diego, USA) 


\section{References}

Allison, C. K., \& Stanton, N. A. (2019). Eco-driving: the role of feedback in reducing emissions from everyday driving behaviours. Theoretical Issues in Ergonomics Science, 20(2), 85-104.

Allison, C. K., Parnell, K. J., Brown, J. W., \& Stanton, N. A. (2017). Modeling the Real World Using STISIM Drive ${ }^{\circledR}$ Simulation Software: A Study Contrasting High and Low Locality Simulations. International Conference on Applied Human Factors and Ergonomics, (pp. 906-915).

Allison, C., Fleming, J., Yan, X., Stanton, N., \& Lot, R. (2019, February). From the Simulator to the Road-Realization of an In-Vehicle Interface to Support FuelEfficient Eco-Driving. In International Conference on Intelligent Human Systems Integration (pp. 814-819). Springer, Cham.

Bangor, A., Kortum, P. T., \& Miller, J. T. (2008). An empirical evaluation of the system usability scale. Intl. Journal of Human--Computer Interaction , 24, 574594.

Banks, V. A., Stanton, N. A., Burnett, G., \& Hermawati, S. (2018). Distributed Cognition on the road: Using EAST to explore future road transportation systems. Applied ergonomics, 68, 258-266.

Barkenbus, J. N. (2010). Eco-driving: An overlooked climate change initiative. Energy Policy , 38, 762-769.

Beusen, B., Broekx, S., Denys, T., Beckx, C., Degraeuwe, B., Gijsbers, M., ... \& Panis, L. I. (2009). Using on-board logging devices to study the longer-term impact of an eco-driving course. Transportation research part D: transport and 39 
environment, 14(7), 514-520.

Birol, F. (2011). CO2 emissions from fuel combustion--highlights.

Birrell, S. A., Young, M. S., \& Weldon, A. M. (2013). Vibrotactile pedals: provision of haptic feedback to support economical driving. Ergonomics , 56, 282-292.

Boriboonsomsin, K., Vu, A., \& Barth, M. (2010). Eco-driving: pilot evaluation of driving behavior changes among us drivers. Tech. rep., University of California Transportation Center.

Botkin, D.B., Saxe, H., Araujo, M.B., Betts, R., Bradshaw, R.H., Cedhagen, T., Chesson, P., Dawson, T.P., Etterson, J.R., Faith, D.P. \& Ferrier, S. (2007). Forecasting the effects of global warming on biodiversity. AIBS Bulletin, 57(3), 227-236.

Brooke, J. (1996). SUS-A quick and dirty usability scale. Usability evaluation in industry, 189, 4-7.

Chan, C. C. (2007). The state of the art of electric, hybrid, and fuel cell vehicles. Proceedings of the IEEE, 95, 704-718.

Dehkordi, S. G., Larue, G. S., Cholette, M. E., Rakotonirainy, A., \& Rakha, H. A. (2019). Ecological and safe driving: A model predictive control approach considering spatial and temporal constraints. Transportation research part D: transport and environment, 67, 208-222.

Delhomme, P., Cristea, M., \& Paran, F. (2013). Self-reported frequency and perceived difficulty of adopting eco-friendly driving behavior according to gender, age, and environmental concern. Transportation Research Part D: Transport and Environment, 20, 55-58. 
Dogan, E., Bolderdijk, J. W., \& Steg, L. (2014). Making small numbers count: environmental and financial feedback in promoting eco-driving behaviours. Journal of Consumer Policy, 37, 413-422.

Earth's CO2 Home Page. (n.d.). Retrieved August 20, 2018, from https://www.co2.earth/

Fischer, G., Shah, M., N. Tubiello, F. \& Van Velhuizen, H. (2005). Socio-economic and climate change impacts on agriculture: an integrated assessment, 19902080. Philosophical Transactions of the Royal Society B: Biological Sciences, 360(1463), pp.2067-2083.

Fleming, J. M., Yan, X., Allison, C. K., Stanton, N. A., \& Lot, R. (2018). Driver Modeling and Implementation of a Fuel-saving ADAS. IEEE Conference on Systems, Man and Cybernetics (SMC).

Fleming, J., Yan, X, \& Lot, R. (2020). Incorporating Driver Preferences Into EcoDriving Assistance Systems Using Optimal Control. IEEE Transactions on Intelligent Transportation Systems

Froehlich, J., Dillahunt, T., Klasnja, P., Mankoff, J., Consolvo, S., Harrison, B., et al. (2009). UbiGreen: investigating a mobile tool for tracking and supporting green transportation habits. Proceedings of the SIGCHI Conference on Human Factors in Computing Systems, (pp. 1043-1052).

Giacomin, H., Unno, M., Eichbauer, K., \& Atkins, C. (2019). Automotive wastes. Water Environment Research, 91(10), 1223-1228.

Guzzella, L., \& Sciarretta, A. (2007). Vehicle propulsion systems (Vol. 1). SpringerVerlag Berlin Heidelberg. 
Hart, S. G., \& Staveland, L. E. (1988). Development of NASA-TLX (Task Load Index): Results of empirical and theoretical research. In Advances in psychology (Vol. 52, pp. 139-183). Elsevier.

Heyes, D., Daun, T. J., Zimmermann, A., \& Lienkamp, M. (2015). The Virtual Driving Coach-design and preliminary testing of a predictive eco-driving assistance system for heavy-duty vehicles. European Transport Research Review, 7(3), 25.

Horberry, T., Anderson, J., Regan, M. A., Triggs, T. J., \& Brown, J. (2006). Driver distraction: The effects of concurrent in-vehicle tasks, road environment complexity and age on driving performance. Accident Analysis \& Prevention, $38(1), 185-191$.

IEA. (2011). CO2 emissions from fuel combustion-highlights. From http://www.iea.org/co2highlights/co2highlights.pdf

IEA. (2017). Key world energy statistics. From https://www.iea.org/publications/freepublications/publication/KeyWorld2017.p $\underline{\mathrm{df}}$

International Energy Agency Staff. (2008). CO2 Emissions from Fuel Combustion: 1972. Organization for Economic.

Jamson, A. H., Hibberd, D. L., \& Merat, N. (2013). The design of haptic gas pedal feedback to support eco-driving. In Proceedings of the Seventh International Driving Symposium on Human Factors in Driver Assessment, Training, and Vehicle Design (pp. 264-270). University of Iowa.

Jamson, S. L., Hibberd, D. L., \& Jamson, A. H. (2015). Drivers' ability to learn eco42 
driving skills; effects on fuel efficient and safe driving behaviour.

Transportation Research Part C: Emerging Technologies , 58, 657-668.

Larue, G. S., Malik, H., Rakotonirainy, A., \& Demmel, S. (2014). Fuel consumption and gas emissions of an automatic transmission vehicle following simple ecodriving instructions on urban roads. IET Intelligent Transport Systems, 8(7), 590-597.

Lorf, C., Martínez-Botas, R. F., Howey, D. A., Lytton, L., \& Cussons, B. (2013). Comparative analysis of the energy consumption and $\mathrm{CO} 2$ emissions of 40 electric, plug-in hybrid electric, hybrid electric and internal combustion engine vehicles. Transportation Research Part D: Transport and Environment , 23, 1219.

Martin, E., Chan, N., \& Shaheen, S. (2012). How public education on ecodriving can reduce both fuel use and greenhouse gas emissions. Transportation Research Record: Journal of the Transportation Research Board, 163-173.

McIlroy, R. C., Stanton, N. A., \& Harvey, C. (2013). Getting drivers to do the right thing: a review of the potential for safely reducing energy consumption through design. IET Intelligent Transport Systems, 8(4), 388-397.

McIlroy, R. C., Stanton, N. A., Godwin, L., \& Wood, A. P. (2017). Encouraging ecodriving with visual, auditory, and vibrotactile stimuli. IEEE Transactions on Human-Machine Systems, 47(5), 661-672.

McMichael, A.J., Woodruff, R.E. \& Hales, S., (2006). Climate change and human health: present and future risks. The Lancet, 367(9513), 859-869.

Meinshausen, M., Meinshausen, N., Hare, W., Raper, S. C., Frieler, K., Knutti, R., et 43 
al. (2009). Greenhouse-gas emission targets for limiting global warming to $2 \mathrm{C}$. Nature , 458, 1158.

Mensing, F., Bideaux, E., Trigui, R., Ribet, J., \& Jeanneret, B. (2014). Eco-driving: An economic or ecologic driving style? Transportation Research Part C: Emerging Technologies , 38, 110-121.

Meschtscherjakov, A., Wilfinger, D., Scherndl, T., \& Tscheligi, M. (2009). Acceptance of future persuasive in-car interfaces towards a more economic driving behaviour. Proceedings of the 1st International Conference on Automotive User Interfaces and Interactive Vehicular Applications, (pp. 81-88). NASA -Task Load Index (TLX): Computerized Version. (1986). Moffett Field. CA: NASA-Ames Research Center, Aerospace Human Factors Research Division. Pampel, S. M., Jamson, S. L., Hibberd, D. L., \& Barnard, Y. (2015). How I reduce fuel consumption: An experimental study on mental models of ecodriving. Transportation Research Part C: Emerging Technologies, 58, 669-680.

Piatkowski, D., Bronson, R., Marshall, W., \& Krizek, K. J. (2014). Measuring the impacts of bike-to-work day events and identifying barriers to increased commuter cycling. Journal of Urban Planning and Development , 141, 04014034.

Rose, G., \& Marfurt, H. (2007). Travel behaviour change impacts of a major ride to work day event. Transportation Research Part A: Policy and Practice , 41, 351364.

Saboohi, Y., \& Farzaneh, H. (2009). Model for developing an eco-driving strategy of a passenger vehicle based on the least fuel consumption. Applied Energy, 
86(10), 1925-1932.

Skeie, R. B., Fuglestvedt, J., Berntsen, T., Lund, M. T., Myhre, G., \& Rypdal, K. (2009). Global temperature change from the transport sectors: Historical development and future scenarios. Atmospheric Environment , 43, 6260-6270.

Stanton, N. A., Plant, K. L., Roberts, A. P., \& Allison, C. K. (2017). Use of highways in the sky and a virtual pad for landing head up display symbology to enable improved helicopter pilots situation awareness and workload in degraded visual conditions. Ergonomics, 1-13.

Stanton, N. A., Plant, K. L., Roberts, A. P., Allison, C. K., \& Harvey, C. (2018). The virtual landing pad: facilitating rotary-wing landing operations in degraded visual environments. Cognition, Technology \& Work, 20(2), 219-232.Thornton, J., \& Covington, H. (2016). Climate change before the court. Nature Geoscience, 9, 3-5.

Tulusan, J., Staake, T., \& Fleisch, E. (2012, September). Providing eco-driving feedback to corporate car drivers: what impact does a smartphone application have on their fuel efficiency? In Proceedings of the 2012 ACM conference on ubiquitous computing (pp. 212-215). ACM.

Turrentine, T. S., \& Kurani, K. S. (2007). Car buyers and fuel economy? Energy policy, 35(2), 1213-1223

Vaezipour, A., Rakotonirainy, A., Haworth, N., \& Delhomme, P. (2018). A simulator evaluation of in-vehicle human machine interfaces for eco-safe driving. Transportation Research Part A: Policy and Practice, 118, 696-713.

Vining, C. B. (2009). An inconvenient truth about thermoelectrics. Nature materials, 45 
$8,83$.

Windecker, A., \& Ruder, A. (2013). Fuel economy, cost, and greenhouse gas results for alternative fuel vehicles in 2011. Transportation Research Part D: Transport and Environment, 23, 34-40.

World Economic Forum, What are the 10 biggest global challenges? Retrieved August 28, 2018, from https://www.weforum.org/agenda/2016/01/what-are-the10-biggest-global-challenges

Yilmaz, M., \& Krein, P. T. (2013). Review of battery charger topologies, charging power levels, and infrastructure for plug-in electric and hybrid vehicles. IEEE Transactions on Power Electronics , 28, 2151-2169.

Young, M. S., Birrell, S. A., \& Stanton, N. A. (2009, July). Design for smart driving: A tale of two interfaces. In International Conference on Engineering Psychology and Cognitive Ergonomics (pp. 477-485). Springer, Berlin, Heidelberg. 